Article

\title{
Wind Farm-LA Coordinated Operation Mode and Dispatch Model in Wind Power Accommodation Promotion
}

\author{
Li Lin *, Xuexuan Cai ${ }^{(\mathbb{D}}$, Bingqian Xu ${ }^{(\mathbb{D})}$ and Shiwei Xia ${ }^{(1)}$ \\ State Key Laboratory of Alternate Electrical Power System with Renewable Energy Sources, North China \\ Electric Power University, Beijing 102206, China; caixuexuan1013@163.com (X.C.); xbq_1132@163.com (B.X.); \\ s.w.xia@ncepu.edu.cn (S.X.) \\ * Correspondence: linli@ncepu.edu.cn
}

Received: 29 March 2018; Accepted: 24 April 2018; Published: 11 May 2018

\begin{abstract}
With the support of a smart grid, a load aggregator (LA) that aggregates the demand response resources of small- and medium-sized customers to participate in the electricity market would be a novel way to promote wind power accommodation. This paper proposes a wind farm-LA coordinated operation mode (WLCOM), which enables LAs to deal with wind farms directly at an agreement price. Afterwards, according to the accommodation demand of the wind farm, a coordinated dispatch model taking advantage of the various response capabilities of different flexible loads is set up to maximize the revenue of the LA. A case study was conducted to demonstrate the effectiveness of the proposed WLCOM and the coordinated dispatch model. The demonstration indicates that: (a) load fluctuations and wind curtailment were obviously reduced; and (b) both the LA and the wind farm participating in coordinated operation obtained higher revenues. Factors that influence the accommodation level, as well as revenues of wind farms and LA, are also investigated.
\end{abstract}

Keywords: demand response; load aggregator; smart grid; cooperative operation

\section{Introduction}

Driven by the initiative to promote the transformation of energy structures and realize sustainable development, China has focused on wind power development in recent years. However, large-scale wind power integration has brought challenges to the operation and dispatch of the power system, due to its randomness, volatility, and serious anti-peaking characteristics. In the conventional dispatch mode, real-time power balance is achieved by load tracking, in which the loads are passive and rigid (i.e., lacking in elasticity). Since thermal generation still dominates in China's power supply structure, there is a shortage of flexible supplies such as hydropower units and gas-fired units and other units with quick response capability. With the high proportion of wind power in the current system, the operational requirements can never be satisfied if the coverage of optimization dispatch is still limited on the generation side, resulting in a considerable amount of wind curtailment. Because of the rapid development of smart grids and the gradual opening of the electricity market, adjusting power user's use of electricity through demand response (DR) is an effective way to ease the problem of wind curtailment and promote wind power accommodation.

DR refers to the market participation behavior of power users, who take the initiative to respond and change the fixed utility mode oriented by market price signals or incentive mechanisms [1,2]. This behavior changes inelastic and non-dispatched "rigid" loads into active, bidirectional, and controllable "flexible" loads. According to user response characteristics, the flexible loads participating in DR programs are divided into three types: curtailable load (the interruptible load), shiftable load, and transferable load [3]. 
As for the application of DR in promoting wind power accommodation, most existing literature, in order to minimize operation cost or maximize social welfare, applies the idea of generation dispatch strategy to consumption dispatch and makes decisions for load response and unit commitment problems. A two-stage stochastic programming model for the hourly scheduling of optimal reserves is presented in [4], and DR is considered for reducing the cost of security-based power system scheduling, solving wind forecast errors. In [5,6], curtailable loads and transferable loads are taken into account to establish a source-load coordination dispatch model. The simulations indicate that the model is intended to improve wind power acceptance capacity, reducing system carbon emissions and transmission congestion. The 2013 paper by Zhao et al. [7] develops a robust optimization approach-consumers' response to price signals is modeled as an uncertain price-elastic demand curve, and the response can help accommodate wind power output by lowering the unit load cost. To account for the users' point of view, consumer participation enthusiasm in DR is also counted in some papers, in which they study corresponding demand response resources (DRRs) dispatch strategies. Maximizing benefits or consumer satisfaction is set as the objective function [8-10]. Specifically, minimum error is regarded as the control objective in [11], and thermostatic loads are used as virtual storage devices to track power output. However, the electricity market is still expected to see greater openness, and the development of a micro grid is only at the experimental stage in China. Hence, in the short run, flexible loads cannot be dispatched directly by the high-voltage power grid to serve for large-scale wind accommodation.

In addition, for the load aggregator (LA), the new market trading entity, the paper by Li et al. [12] establishes a double-layer real-time dispatch model of the dispatch center. At the macro layer, the dispatch priority of each LA is determined, then the load allocation strategy of the LA is studied according to the degree of user contribution at the micro level. Squaring up to interruptible loads and electric vehicles aggregated by LAs, the simultaneous dispatch is proposed, and aiming at the uncertainties of wind and photovoltaic (PV) powers, a developed two-stage model is presented to reduce the operation cost of a microgrid in [13]. Due to the relatively high regulating capacity of high-energy loads represented by the wood industry [14,15], in terms of local accommodation, the paper presents a joint operation mode of a high-energy load and wind power. However, the fact that high energy loads distribute regionally narrows the applicable range of those models [16]. In the above studies, LAs, high-energy loads, or wind farms just passively accept dispatch, resulting in the possibility that adjustment will be hindered and revenues will be damaged. China is undergoing a new round of electric power reform, as the electricity market and the smart grid technology both become more mature. One benefit of this is that electricity retailers can directly deal with power generation companies. Such transactions are not subject to geographical constraints, so participants have the possibility of obtaining higher revenues. In connection with this situation, the paper by Huang et al. [17] investigates electric vehicle charging dispatch to match the charging load with wind power, and the dispatch is carried out on the level of aggregators. However, electric vehicles in China are still not popular enough. To the best of our knowledge, there are not yet works proposing the possible operation between wind farms and LAs. In this paper, this operation is designed to fill in the gaps of this field.

Contributions of this paper are listed below:

1. A wind farm-LA coordinated operation mode (WLCOM) is proposed. In WLCOM, the LA deals directly with wind farms at an agreement price, accommodating wind power actively. According to possible wind curtailment forecasts, the wind farm provides the LA with day-ahead accommodation demand, allowing the LA to complete a reasonable load dispatch plan in advance.

2. In WLCOM, making use of the particular response capabilities of different flexible loads, a coordinated dispatch model is established to maximize the revenue of LAs based on the accommodation demand of the wind farm. 
3. Benefit analysis is conducted to verify the economy of coordinated operation. Factors influencing the accommodation level, as well as revenues of the wind farm and the LA (in particular, the agreement price and the compensation price) are also investigated.

This paper is organized as follows: In Section 2, we introduce the definition of a LA and describe the smart grid technologies that a LA uses to take part in the interaction between DRR demanders and flexible loads. Section 3 proposes the WLCOM and gives the LA's response model referring to $[18,19]$. Section 4 establishes the coordinated dispatch model. Simulations are given in Section 5 to prove the effectiveness of the proposed model in this paper. Finally, in Section 6, the conclusions and key innovations are further emphasized.

\section{LA Applied in a Smart Grid}

\subsection{Introduction to $L A$}

In the conventional power market, DR is mainly aimed at large industrial and commercial customers whose electricity loads are easily managed and who have relatively high demand elasticity. However, for small- and medium-sized customers (SMCs) (such as residents and small commercial customers), it is difficult to directly participate in the market despite their capability and willingness, because of their low elasticity. Owing to the development bottleneck of demand response resources (DRRs) for large customers, market developers are gradually turning their attention to SMCs. When this happens, the LA emerges and acts as a connection between the loads and the market.

Until now, there has been no formal or widely-accepted definition of LAs. The California Independent System Operator (CAISO) defines a LA as an organization entity that provides a load curtailment service for an independent system operator (ISO)—for example, an energy service provider or a distribution company [20]. In [21] a LA is defined as an entity playing the middleman role in the power market. It provides customers with more valid ways to engage in the market, and provides the market with more flexible techniques and services. LAs are also further described as gathering together, exploiting load response potential, and coordinating a set of dispersed DRRs to provide specific services to the grid by specialized commercial and technical means in exchange for monetary benefits [22].

The electricity retail market in China is currently experiencing reform, which will further enrich power market mechanisms and diversify participants [23]. LAs performing as power-sellers, aggregating both fixed and responsive flexible loads of SMCs to participate in the power market initiatively, is a win-win situation. Additionally, because of severe energy shortages and environmental pollution problems, it is essential to accurately excavate DRRs from SMCs. In this complex scenario, the actualization of LAs in China is provided with the opportunity and environment for the promotion of LAs in China.

\subsection{Technical Support of Smart Grids}

Robust technical support from a smart grid is fundamental when engaging LAs in initiative, bidirectional, and controllable interactions between DRRs buyers and loads.

The definition of a smart grid varies between countries, but the basic concept refers to a means of pursuing safe, reliable, economical, efficient, and clean operation and to maximize social benefits. In contrast to conventional power grids, it particularly emphasizes interactions with customers on information and electric energy. Meanwhile, the technical system centered on the advanced metering infrastructure (AMI) of smart grids exactly plays a key role in supporting DR and tightening interactions [24,25]. By using smart meters, LAs are envisioned to collect and calculate electricity consumption information, as well as analyze the consumption characteristics and laws in order to provide data support for customer participation in DR. Moreover, real-time, high-speed, and integrated bidirectional communication technology safeguards information interactions between LAs and DRRs buyers, and between customers and LAs, as well as smart electric equipment. Backed by the 
bidirectional communication system, buyers' purchase demands are sent to the LA. Then, the LA feeds back available DR services and simultaneously sends dispatch commands to customers after overall considerations about the purchase demands and aggregated resources. Additionally, the installation of smart electric equipment guarantees rational power distribution and timely response for customers.

Hence, smart grids and LAs are closely associated. By building an open and intercommunicating information system, coupled with advanced control and communication techniques, a smart grid efficiently aggregates electric power system data, and supports LA implementation [26].

\section{Wind Farm-LA Coordinated Operation Mode in Wind Power Accommodation Promotion}

\subsection{Wind Farm-LA Coordinated Operation Mode}

Since the storage and distribution of wind energy resources does not align with power load centers, China mainly adopts the method of large-scale centralized exploitation and long-distance transmission in wind power development, meaning that large-scale wind farms are the main sources of wind power. After large-scale wind power integration, the accommodation of wind power has become a challenging problem. On the one hand, the low adjustment capacity problem of conventional power supply arises, because the power system is constrained by system reserve capacity, unit ramp rate, minimum stable output, etc. When a power grid is confronted with difficulty in accommodating all wind power output, wind farms will be prevented from delivering their full potential and then a part of the wind source will be abandoned. A case study of Gansu Province, the core region of wind power development in China, shows a considerable amount of "curtailed wind". The wind abandon rate was $43 \%$ in 2016, and the curtailed electricity reached 10,400 MkWh [27]. Thus, there is a strong need to reduce curtailed wind energy. In addition, because of the cost of wind power is so low that it can be neglected, this need is rational and will further expand profits. On the other hand, with the technical support from a smart grid, if a LA could buy curtailed electricity from wind farms at a low price and accommodate it by dispatching the aggregated flexible loads, both wind farms and the LA would gain profits, which would be a win-win situation. Therefore, in this paper, WLCOM with technical support from a smart grid is proposed to realize the source-load interactions, as is shown in Figure 1.

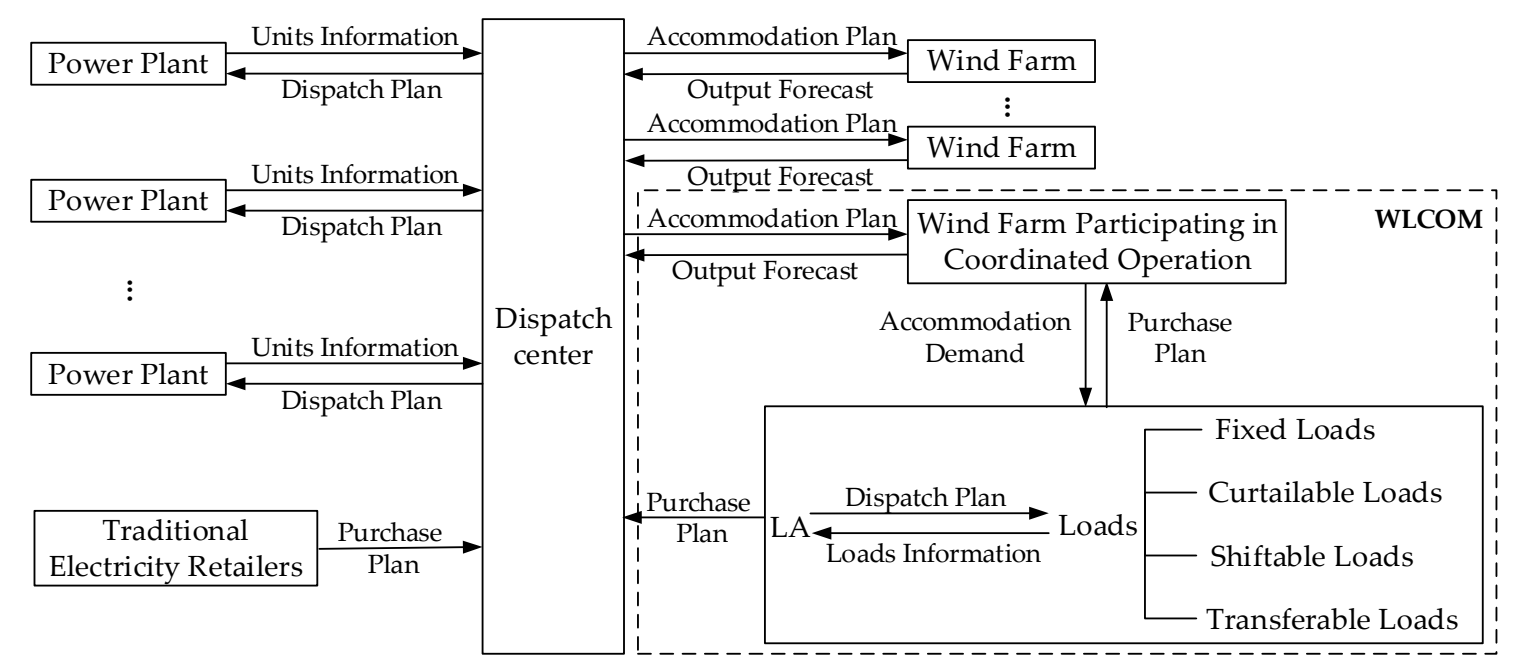

Figure 1. Schematic diagram of wind farm-load aggregator (LA) coordinated operation mode (WLCOM).

According to the day-ahead wind power forecast, loads forecast (including conventional loads and loads aggregated by the LA), and conventional power supply adjustment capacity, the dispatch center makes a conventional power supply generation plan as well as a wind power integration plan. The difference between day-ahead predicted and planned wind power output is excess output, which is also defined as accommodation demand. Wind farms sell the excess output to the LA directly at 
the price determined in consultation, which is lower than the pool sale price. Then, in view of the demand and the aggregated flexible loads response capabilities, the LA dispatches these loads to consume residual power. If excess output cannot satisfy load demand, the LA will send a purchase plan to the center, buying electricity from the power grid to compensate for the shortage, and it is required that the LA should give priority to buying electricity from wind farms. The dispatch center will make adjustments to the dispatch plan of power plants (wind farms are not included) according to the purchase plan of the LA. Additionally, contracts signed by the LA and the aggregated loads will constrain load response characteristics as well as the compensatory price. Thus, under the background of a smart grid, information is shared between the power grid, wind farms, and the LA. Apart from this interaction, dealing with each other and accounting independently is possible without being influenced.

\subsection{LA Response Model in Cooperation}

Aggregated loads include fixed loads and flexible loads, wherein the flexible loads include curtailable loads, shiftable loads, and transferable loads. Compared to flexible loads, fixed loads are so rigid that they should be ensured a reliable power supply by the LA. Curtailable loads have lower demands for power supply reliability, and when needed, are mandatory to curtail all or part of loads [28], such as lighting and thermostatic loads (represented by air conditioning and refrigerators). Shiftable loads are restricted by production or life processes and are likely to be shifted in time [29], such as industrial equipment (like pipelines) and household appliances (like washing machines, dishwashers), which usually consume electricity continuously and are time-fixed. Transferable loads require the total electricity consumption to remain unchanged in a scheduling cycle, but in each period of one cycle the consumption can be without limit (e.g., energy storage devices, electric vehicle charging stations) [30]. Models of these three types of flexible loads are as follows.

\subsubsection{Curtailable Loads Model}

A $0-1$ variable $u(i, t)$ is defined as the status of the $i$ th curtailable load in the theriod. If $u(i, t)=1$, then the load is curtailed during the $t$ th period and the $i$ th power after dispatch, $P_{\text {cut }}(i, t)$, is stated as:

$$
P_{\text {cut }}(i, t)=P_{c u t}^{*}(i, t)-u(i, t) \Delta P_{\text {cut }}(i, t)
$$

where $P_{c u t}^{*}(i, t)$ represents the electricity consumption of the $i$ th load in the $t$ th period before dispatch; $\Delta P_{\text {cut }}(i, t)$ represents the curtailed power in the $t$ th period.

\subsubsection{Shiftable Loads Model}

Assume that the $j$ th shiftable load starts to consume electricity in the $t_{*}(j)$ th period, lasting for $t_{o n}(j)$ periods, and can be shifted during period $\left[t_{s h-}(j), t_{s h+}(j)\right]$. We define $0-1$ variable $y(j, \tau)$ as the initial status in period $\tau$. If the $j$ th load starts operating in period $\tau$, then $y(j, \tau)=1$. Set $S_{\text {shift }}(j)$ is the possible start time of the $j$ th load.

$$
S_{\text {shift }}(j)=\left[t_{\text {sh- }}(j), t_{s h+}(j)-t_{\text {on }}(j)+1\right] \cup t_{*}(j)
$$

If $\tau=t_{*}(j)$, then the $j$ th load is not shifted. Else if $\tau \neq t_{*}(j)$ and $\tau \in S_{\text {shift }}(j)$, then the $j$ th load is shifted to period $\tau$ to start operating. Suppose that there are $T$ periods of time in a scheduling cycle, and the row vector $P_{\text {shift }}(j, \tau)$ describing the power distribution of $j$ that corresponds to $y(j, \tau)$ will be as follows:

$$
P_{\text {shift }}(j, \tau)=\left(0, \cdots, P_{\text {shift }}(j, 1), P_{\text {shift }}(j, 2), \cdots, P_{\text {shift }}\left(j, t_{\text {on }}(j)\right), \cdots, 0\right), \tau \in S_{\text {shift }}(j)
$$

where $P_{\text {shift }}(j, 1), P_{\text {shift }}(j, 2), \cdots, P_{\text {shift }}\left(j, t_{\text {on }}(j)\right)$ represent the electricity consumption of the $j$ th load at each period. $P_{\text {shift }}(j, 1)$ is in period $\tau$; by the same token, $P_{\text {shift }}\left(j, t_{\text {on }}(j)\right)$ is in period $\left(\tau+t_{\text {on }}(j)-1\right)$. 
Then, the power of the $j$ th shiftable load after dispatch in the $t$ th period can be calculated using the following formula:

$$
P_{\text {shift }}(j, t)=\left(\sum_{\tau \in S_{\text {shift }}(j)} y(j, \tau) P_{\text {shift }}(j, \tau)\right)
$$

where $(\cdot)_{t}$ is the th element of vector $(\cdot)$.

\subsubsection{Transferable Loads Model}

Define two 0-1 variables $v\left(k, t^{\prime}, t\right), w\left(k, t, t^{\prime}\right)$ as the status of the $k$ th transferable load transfers in the $t$ th period from the $t^{\prime}$ th period and out from the $t$ th period to the $t^{\prime}$ th period. When the value is 1 , it means the transfer happens. Then, we have the power of the $k$ th load in the $t$ th period.

$$
P_{\text {trans }}(k, t)=P_{\text {trans }}^{*}(k, t)+\sum_{t^{\prime}=1, t^{\prime} \neq t}^{t}\left[v\left(k, t^{\prime}, t\right)-w\left(k, t, t^{\prime}\right)\right] \Delta P_{\text {trans }}(k)
$$

where $P_{\text {trans }}^{*}(k, t)$ represents the power of the $k$ th load before dispatch and $\Delta P_{\text {trans }}(k)$ represents transferring power.

If the power of fixed loads in the $t$ th period is denoted as $P_{f i x}(m, t)$, the total loads of the LA in the $t$ th period, $P_{\text {sum }}(t)$, can be stated as:

$$
P_{\text {sum }}(t)=\sum_{i=1}^{N_{\text {cut }}} P_{\text {cut }}(i, t)+\sum_{j=1}^{N_{\text {shift }}} P_{\text {shift }}(j, t)+\sum_{k=1}^{N_{\text {trans }}} P_{\text {trans }}(k, t)+\sum_{m=1}^{N_{\text {fix }}} P_{\text {fix }}(m, t)
$$

where $N_{\text {cut }}, N_{\text {shift }}, N_{\text {trans }}$, and $N_{\text {fix }}$ denote the number of curtailable loads, shiftable loads, transferable loads, and fixed loads.

\section{Wind Farm-Load Coordinated Dispatch Model}

\subsection{Objective Function}

Let $R$ be the total revenue of LA and $C_{\text {sell }}, C_{b u y}$, and $C_{\text {com }}$ denote the LA's electricity sale revenue, purchase costs, and compensation costs, respectively. Accordingly, under the premise of meeting fixed loads' electricity demands and constraints on the LA's internal power balance, the LA dispatches loads legitimately in light of the response capacity of different types of flexible loads, and the objective function is to maximize $R$ in a scheduling cycle.

$$
\begin{aligned}
\max R=\max \left(C_{\text {sell }}\right. & \left.-C_{\text {buy }}-C_{\text {com }}\right)=\max \left[c_{\text {sell }} E_{\text {sum }}-\left(c_{\text {wind }} E_{\text {wind }}+c_{\text {grid }} E_{\text {grid }}\right)\right. \\
& \left.-\left(c_{\text {cut }} P_{\text {sum }}^{\text {cut }}+c_{\text {shift }} P_{\text {sum }}^{\text {shift }}+c_{\text {trans }} P_{\text {sum }}^{\text {trans }}\right)\right]
\end{aligned}
$$

where $P_{\text {sum }}^{\text {cut }}, P_{\text {sum }}^{\text {shift }}$, and $P_{\text {sum }}^{\text {trans }}$ respectively represent the sum of power that loads curtail, shift and transfer; $c_{w i n d}$ and $c_{\text {grid }}$ are the per-unit price at which the LA buys electricity from wind farms and the power grid, respectively; $E_{\text {sum }}$ is the total electricity of all loads. Namely, the integral of $P_{t}^{\text {sum }}$ appearing in Equation (6), and $E_{\text {wind }}, E_{\text {grid }}$ are respectively the electricity which the LA buys from wind farms and the power grid. So, we have this equation $E_{\text {sum }}=E_{\text {wind }}+E_{\text {grid }}$. Besides, $c_{c u t}, c_{\text {shift }}$, and $c_{\text {trans }}$ are respectively the compensation prices of unit power that loads curtail, shift, and transfer.

\subsection{Equality and Inequality Constraints}

1. Constraints on power balance

Let $P_{\text {wind }}(t)$ and $P_{\text {grid }}(t)$ be the power that the LA receives from the wind farms and the power grid in the $t$ th period, respectively:

$$
P_{\text {sum }}(t)=P_{\text {wind }}(t)+P_{\text {grid }}(t) .
$$


2. Constraints on flexible loads

(a) Curtailable loads

- The maximum number of curtailment

$$
\sum_{t=1}^{t} u(i, t)[1-u(i, t)] \leq N_{\max }^{c u t}(i)
$$

- The longest load-curtailment duration

$$
\sum_{t=n}^{n+T_{\max }^{c u t}(i)} u(i, t) \leq T_{\max }^{c u t}(i), n=1,2, \cdots, T-T_{\max }^{c u t}(i)
$$

- The shortest curtailment interval

$$
[u(i, t-1)-u(i, t)]\left[T_{c u t}(i, t-1)-T_{\min }^{c u t}(i)\right] \leq 0
$$

- load-curtailment capacity

$$
P_{\min }^{c u t}(i) \leq \Delta P_{\text {cut }}(i, t) \leq P_{\max }^{c u t}(i)
$$

In these equations, $N_{\max }^{\text {cut }}(i)$ represents the maximum curtailment frequency of the $i$ th load in a scheduling cycle; $T_{\max }^{c u t}(i), T_{\min }^{c u t}(i)$, and $T_{c u t}(i, t-1)$ are respectively the longest load-curtailment duration, the shortest curtailment interval, and the cumulative non-curtailment interval in the $t$ th period. $P_{\max }^{c u t}(i)$ and $P_{\min }^{c u t}(i)$ are the allowable maximum and minimum curtailment capacity, respectively.

(b) Shiftable loads

After dispatch, shiftable loads only have two possible cases, either not shifted or shifted to an acceptable time interval, which can be expressed as:

$$
\begin{aligned}
\sum_{\tau \in S_{\text {shift }}(j)} y(j, \tau) & =1 \\
\sum_{\tau \notin S_{\text {shift }}(j)} y(j, \tau) & =0
\end{aligned}
$$

(c) Transferable loads

- $\quad$ Transferable period

$$
v\left(k, t^{\prime}, t\right)=0, t \notin\left[t_{t r-}(k), t_{t r+}(k)\right]
$$

- Prohibition of loads transfer in and out at the same time

$$
\sum_{t^{\prime}=1, t^{\prime} \neq t}^{t}\left[v\left(k, t^{\prime}, t\right)+w\left(k, t, t^{\prime}\right)\right] \leq 1
$$

- The fixed amount of electricity loads require

$$
\sum_{t=t_{\text {tr }}(k)}^{t_{\text {tr }}(k)} P_{\text {trans }}(k, t) \Delta t=E_{\text {trans }}(k)
$$


In the equations, $\left[t_{t r-}(k), t_{t r+}(k)\right]$ is the acceptable time interval of the $k$ th load, $\Delta t$ represents the time of each scheduling period, and $E_{\text {trans }}(k)$ is the total electricity that the $k$ th load consumes in a scheduling cycle.

\subsection{Simulation Method}

In LA day-ahead dispatch, the operation status and operation times of each flexible load are multivariate and discrete mixed integer nonlinear programming (MILP) problems (after performing some processing on Equation (1) to avoid multiplication of two variables). The General Algebraic Modeling System (GAMS) is an advanced modeling system for mathematical planning and optimization, specially designed for linear, nonlinear, and mixed integer optimization problems [31]. Its advantage lies in its simple, clear user interface and its strong, stable numerical analysis capabilities [32]. In view of the applicability of GAMS software in analyzing such problems, we chose it to solve our model in this paper. There are many solvers in GAMS, such as CPLEX, and different solvers use different algorithms to solve models. We choose CPLEX to solve our model with the branch and bound $(B \& B)$ method used.

The basic idea of the $B \& B$ method is to search all feasible solutions (limited by numbers) of the optimization problem with constraints. The feasible solution space is continuously partitioned into smaller subsets (which are so called branches), and a lower or upper bound will be calculated for the value of the solution in each subset, until a feasible solution is found.

\section{Simulation and Results}

\subsection{Case}

The actual wind farm selected to partake in wind farm-LA coordinated operation had a capacity of $749 \mathrm{MW}$, and the total capacity of loads controlled by the LA was $450 \mathrm{MW}$, of which the fixed loads, curtailable loads, shiftable loads, and transferable loads were respectively $310 \mathrm{MW}, 45 \mathrm{MW}, 50 \mathrm{MW}$, and $45 \mathrm{MW}$. Affected by factors such as heating, the wind farm abandoned a great deal of wind power during a winter day. Its curtailed power before coordinated operation (i.e., accommodation demand) is shown in Figure 2 with the daily LA loads forecast curve shown in Figure 3 and the contract data of flexible loads participating in DR shown in Tables 1-3. We assumed that in order to dispatch curtailable loads, shiftable loads, and transferable loads, the costs which the LA needs to compensate for were $¥ 40 / \mathrm{MW}, ¥ 30 / \mathrm{MW}$, and $¥ 20 / \mathrm{MW}$, respectively, and the agreement price at which the LA buys electricity from the wind farm was $¥ 350 / \mathrm{MWh}$. According to the National Energy Administration of People's Republic of China (PRC), "2015 National Electricity Prices Regulatory Reporting", the LA bought electricity from the power grid at the price of $¥ 426.85 / \mathrm{MWh}$, in contrast to $¥ 548.04 / \mathrm{MWh}$, the price at which loads bought electricity from a power grid. The computation time of our model was $0.03-0.05 \mathrm{~s}$.

Table 1. Contract data of curtailable loads.

\begin{tabular}{cccccc}
\hline $\boldsymbol{i}$ & $\boldsymbol{N}_{\max }^{\text {cut }}(\boldsymbol{i})$ & $\boldsymbol{T}_{\max }^{\text {cut }}(\boldsymbol{i})$ & $\boldsymbol{T}_{\min }^{\text {cut }}(\boldsymbol{i})$ & $\boldsymbol{P}_{\min }^{\text {cut }}(\boldsymbol{i})(\mathbf{M W})$ & $\boldsymbol{P}_{\max }^{\text {cut }}(\boldsymbol{i})(\mathbf{M W})$ \\
\hline 1 & 3 & 2 & 2 & 2 & 10 \\
2 & 2 & 4 & 3 & 4 & 15 \\
3 & 3 & 3 & 4 & 1 & 5 \\
\hline
\end{tabular}

Table 2. Contract data of shiftable loads.

\begin{tabular}{ccccc}
\hline$j$ & $\boldsymbol{t}_{\boldsymbol{o n}}(\boldsymbol{j})$ & $\boldsymbol{t}_{*}(j)$ & $\boldsymbol{t}_{\boldsymbol{s h}-}(j)$ & $\boldsymbol{t}_{\boldsymbol{s h}+}(\boldsymbol{j})$ \\
\hline 1 & 3 & 9 & 8 & 24 \\
2 & 4 & 10 & 1 & 22 \\
\hline
\end{tabular}


Table 3. Contract data of transferable loads.

\begin{tabular}{ccccc}
\hline $\boldsymbol{k}$ & $\boldsymbol{t}_{\boldsymbol{t r}-}(\boldsymbol{k})$ & $\boldsymbol{t}_{\boldsymbol{t r +}+}(\boldsymbol{k})$ & $\boldsymbol{E}_{\text {trans }}(\boldsymbol{k})(\mathbf{M W h})$ & $\boldsymbol{\Delta} \boldsymbol{P}_{\text {trans }}(\boldsymbol{k})(\mathbf{M W})$ \\
\hline 1 & 5 & 22 & 30 & 5 \\
2 & 3 & 21 & 60 & 15 \\
3 & 8 & 24 & 30 & 8 \\
\hline
\end{tabular}

$\multimap$ before coordinated operation $\rightarrow-$ after coordinated operation

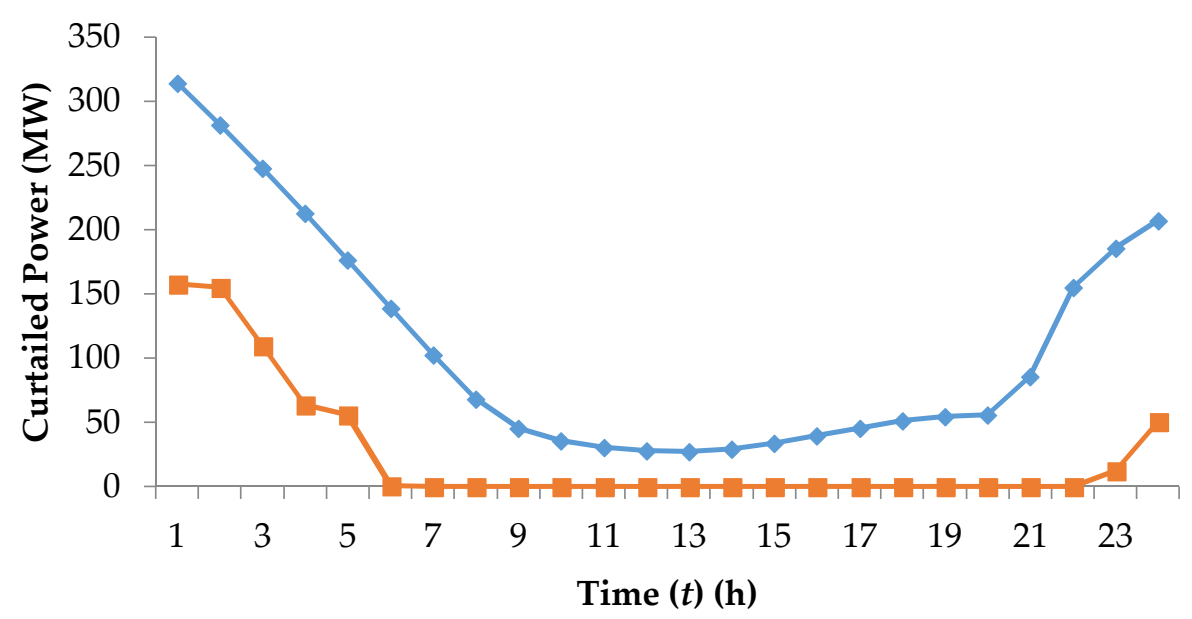

Figure 2. Wind curtailment before/after coordinated operation.

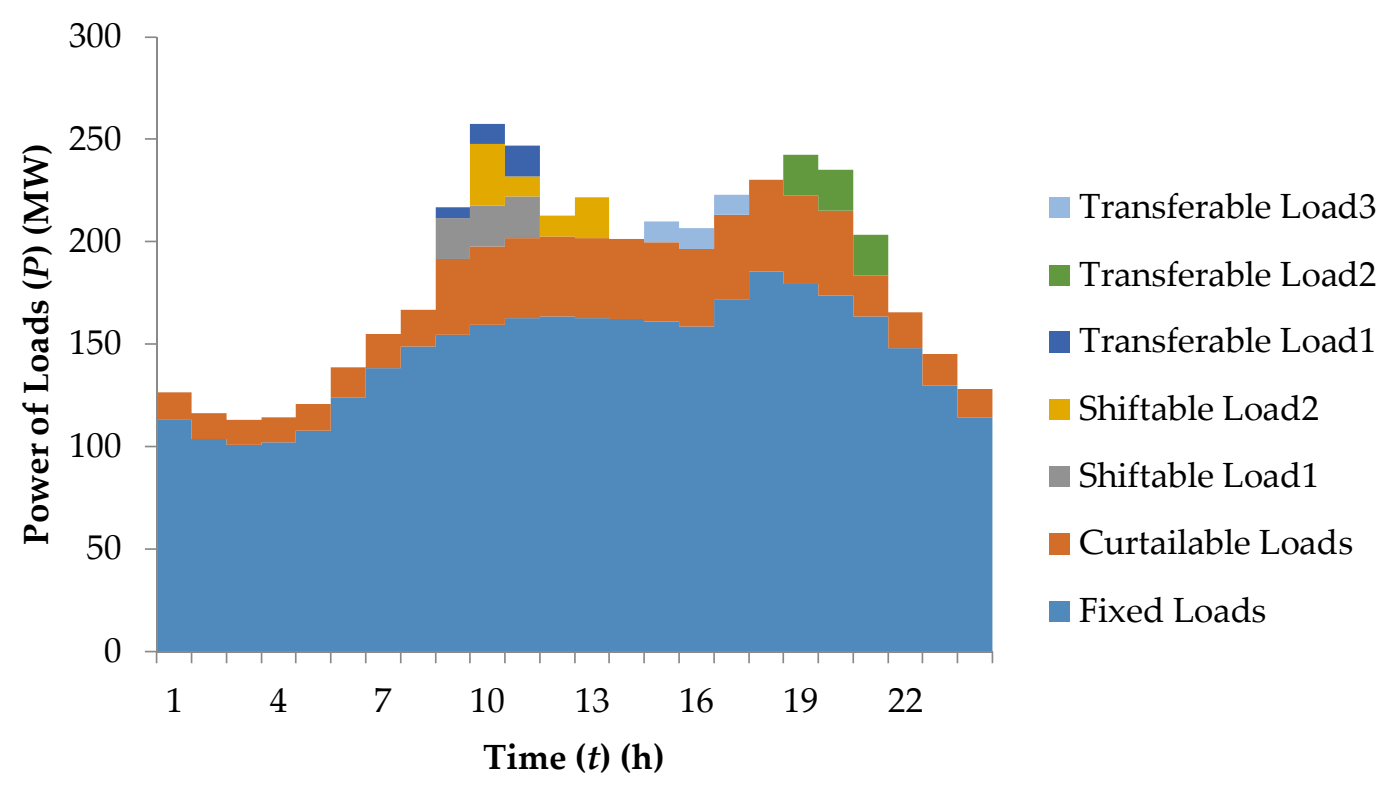

Figure 3. Daily load forecast curve.

\subsection{Case Analysis}

\subsubsection{Analysis of the Day-Ahead Dispatch Results in WLCOM}

On the basis of the wind farm-load coordinated dispatch model promoted in this paper, we simulated the case and got a new daily loads curve after the LA dispatched flexible loads (Figure 4). Comparing Figure 4 with Figure 3, we conclude that: 
- The daily loads curve in Figure 3 shows an obvious morning and evening peak, and the peak-valley difference was 144.68 MW. The curve in Figure 4, i.e., daily loads after dispatch, shows peak shifting and the loads peak-valley difference with a decrease of 35.4 MW compared to that in Figure 3 was 109.28 MW, which means there was an overt reduction of daily loads fluctuations.

- As is seen in Figure 3, shiftable loads consumed power during the morning peak. Compared with that, shiftable load1 was shifted to 22-24 o'clock and shiftable load2 was shifted to 1-4 o'clock in Figure 4, which effectively accommodated the excess nocturnal wind power output, easing the power supply pressure during the morning peak hour.

- The electricity consumption of transferable loads after dispatch is displayed in Table 4, from which it can be seen that transferable loads were divided into several parts in transferable time to play the roles of peak shaving and valley filling flexibly.

- It is worth mentioning that in the scheduling cycle, curtailable loads were not dispatched. This is because power terminal customers can usually afford all or part of the extra costs caused by wind accommodation in China [33], and in this paper we assume that wind farms only have the demand to accommodate curtailed wind (i.e., accommodation demand $\geq 0$ ). In that case, load curtailment will harm the LA's interests and make it unwilling to curtail loads. Actually, to incentivize wind farms to improve forecast accuracy, some European countries (e.g., Denmark, the Netherlands, UK, and Poland) adopt a more rational mechanism so that wind farms receive penalties for positive (negative) errors of power forecast [34], which means it is possible that wind farms' accommodation demands are negative. That is, wind farms need to buy a certain amount of DRRs from the LA in some cases. Due to space issues, this scenario is not discussed in this paper.

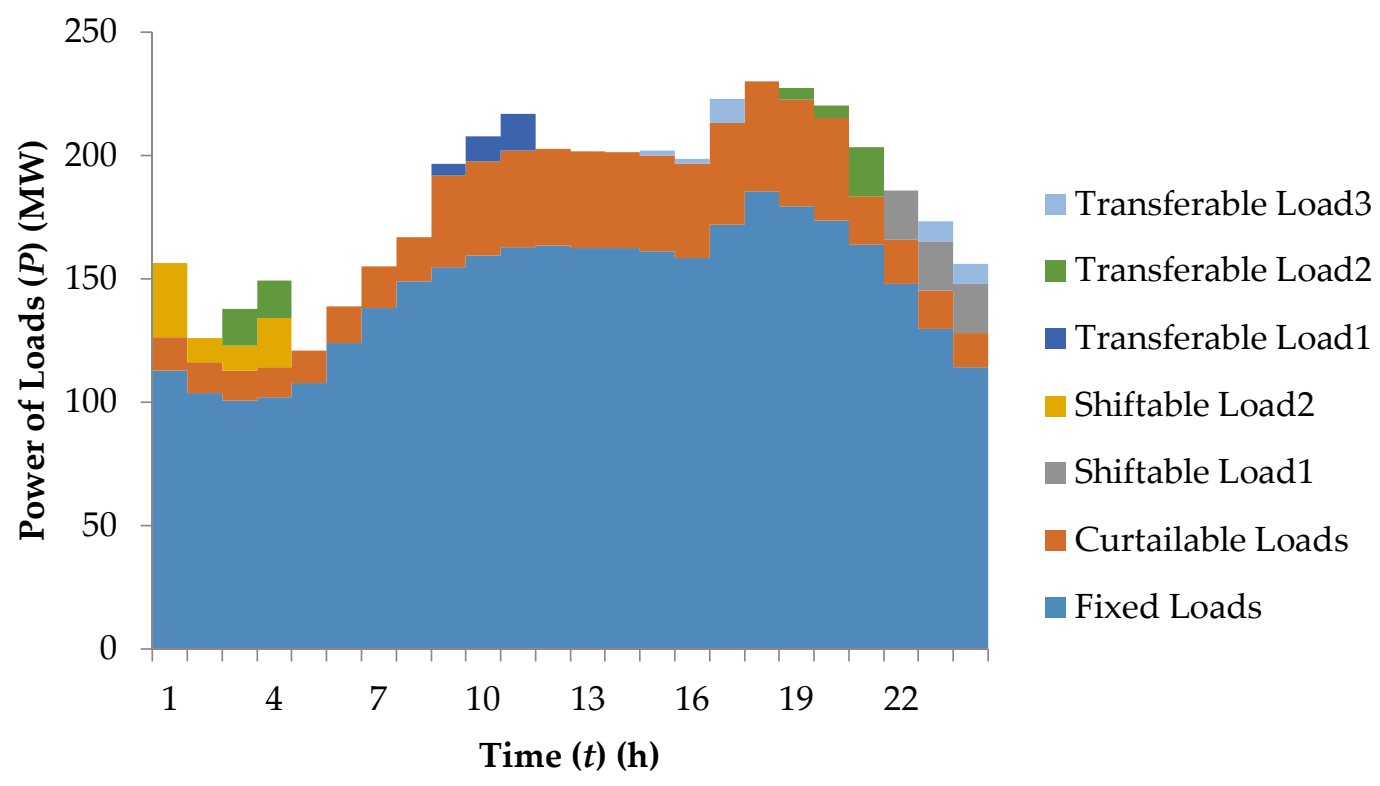

Figure 4. Load curve after dispatch.

Table 4. Power consumption of transferable loads after dispatch.

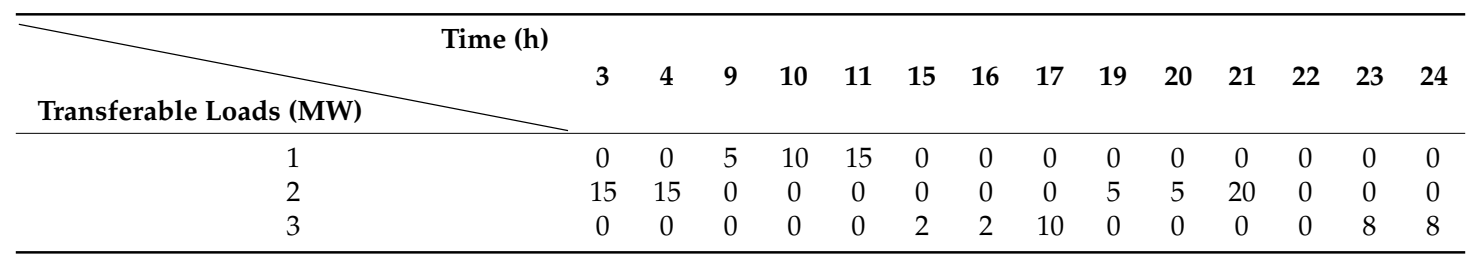




\subsubsection{Benefit Analysis}

Benefit contrasts of the wind farm and the LA are indicated in Table 5 (both before and after coordinated operation). Before the coordinated operation, according to Figure 2, the wind farm was forced to abandon all excess output, which reached 2657.12 MWh. Meanwhile, the LA was supposed to buy all electricity from a power grid, earning $¥ 532,700$ through spread trading. After coordinated operation (also shown in Figure 2), the curtailed wind energy was $607.74 \mathrm{MWh}$, which was $77.13 \%$ lower than before. Hence, the wind farm could earn $¥ 717,300$. Additionally, because loads managed by the LA were not curtailed, the total electricity consumption of those loads remained unchanged (both were $4395.75 \mathrm{MWh}$ ); that is to say, the sale revenue of the LA remained the same (as shown in Tables 6-8 with the purchase of electricity and compensation expenditures). Above all, we must mention that the LA is allowed to buy electricity separately from the wind farm and the power grid. It is indicated that although the LA needed to subsidize flexible loads to make them accept dispatch, the purchase costs were reduced through electricity purchase from the wind farm directly and finally the LA could earn $¥ 686,600$ with an increase of $¥ 153,900$ from before. So, we conclude that by using the WLCOM promoted in this paper, wind energy can be fully utilized to reduce wind curtailment and to substantially increase the revenues of the wind farm and the LA.

However, there are wind power prediction errors, so the day-ahead excess output power of the wind farm sent to the LA is not always equal to its actual values, which may impact the LA's revenue. This is assuming that there is wind power prediction error in each period and the error will not affect the dispatch plan of the LA. If errors are all negative, the electricity purchase cost of the LA will increase during the time when it accommodates all winds, owing to partial electricity purchased from the grid instead of the wind farm. Conversely, if errors are all positive, there will be no loss to the LA. When errors are randomly positive and negative, the loss of the LA will lie in the middle of the two previous cases. Therefore, wind farms must pay the LA a penalty fee when the LA's interest is damaged.

In our case, we supposed that the error was 5\% (all negative), and the wind farm should compensate $80 \%$ of the LA's loss. Then, the increased cost of the LA was $¥ 3958.54$, as a result of $51.51 \mathrm{MWh}$ of electricity purchased from the grid in 6-22 o'clock, and the penalty fee was $¥ 3166.83$. Essentially, because the LA's dispatch is likely to change, the losses of the LA and the wind farm should be reanalyzed accordingly. For this reason, making the day-ahead dispatch plan considering the errors, or establishing a rolling dispatch model considering multi-scale DRRs, either of which targets at accommodation demand of wind farms to improve the robustness of the dispatch results is worthy of further study. Note that this scenario is not discussed in this paper because of space limitations. Above all, to guarantee the interests of both sides, the wind farm still needs to enhance its own prediction accuracy.

Table 5. Revenues comparison between wind farm and load aggregator (LA) before and after coordinated operation.

\begin{tabular}{cccc}
\hline Status & $\begin{array}{c}\text { Curtailed Electricity } \\
\text { (MWh) }\end{array}$ & $\begin{array}{c}\text { Value of Curtailed } \\
\text { Electricity (¥) }\end{array}$ & Instruction \\
\hline $\begin{array}{c}\text { Before Coordinated } \\
\text { Operation }\end{array}$ & 2657.12 & $1,578,400$ & $\begin{array}{c}\text { The wind farm loses } \\
¥ 1,578,400 . \\
\text { LA gains } ¥ 532,700 .\end{array}$ \\
\hline $\begin{array}{c}\text { After Coordinated } \\
\text { Operation }\end{array}$ & $\begin{array}{c}607.74 \\
(\downarrow 77.13 \%)\end{array}$ & 361,000 & $\begin{array}{c}\text { The wind farm loses } \\
¥ 717,300 . \\
\text { LA gains } ¥ 686,600 .\end{array}$ \\
\hline
\end{tabular}

Note: Value of Curtailed Electricity $=$ Curtailed Electricity $\times$ On-Grid Price of Wind Power. 
Table 6. LA revenue after coordinated operation.

\begin{tabular}{ccc}
\hline Types of Loads & Consumed Electricity (MWh) & Revenue (¥) \\
\hline Fixed loads & 3487.84 & $1,911,500$ \\
Curtailable loads & 657.90 & 360,600 \\
Shiftable loads & 130.00 & 71,200 \\
Transferable loads & 120.00 & 65,800 \\
Sum & 4395.75 & $2,409,000$ \\
\hline
\end{tabular}

Table 7. Power purchase of LA after coordinated operation.

\begin{tabular}{ccc}
\hline Types of Purchase & Purchased Electricity (MWh) & Expenditures (¥) \\
\hline Purchase in Coordinated Operation & 2049.38 & 717,300 \\
Purchase from Power Grid & 2346.37 & $1,001,500$ \\
Sum & 4395.75 & $1,718,800$ \\
\hline
\end{tabular}

Table 8. Compensation of LA after coordinated operation.

\begin{tabular}{ccc}
\hline Types of Loads & Dispatch Power (MW) & Expenditures (¥) \\
\hline Curtailable loads & 0 & 0 \\
Shiftable loads & 130.00 & 3900 \\
Transferable loads & 46.00 & 920 \\
Sum & 176.00 & 4820 \\
\hline
\end{tabular}

\subsubsection{Influencing Factors}

The following conclusions were drawn from the simulation results:

- The greater the quantity of loads aggregated by the LA, the greater their capacity and the stronger their response capability, and the better the effect of wind power accommodation, since the power consumption of loads after dispatch can better satisfy the accommodation demand of the wind farm.

- Both shiftable loads and transferable loads have a significant effect on wind accommodation. Comparatively, transferable loads are more flexible due to the lack of temporal and persistent constraints on electricity consumption, and consequently are better at wind accommodation.

- In coordinated operation mode, both flexible loads and fixed loads of the LA can accommodate wind power. Because of the high proportion of fixed loads in this case, in the period when the excess output of the wind farm was greater than the fixed loads electricity demand, they could accommodate up to $95.03 \%$ of curtailed wind energy. As the proportion of flexible loads was low at only $31.11 \%$ (about half of the fixed loads capacity), they could still achieve $29.79 \%$ of the curtailed wind accommodation at peak hours, and greatly enhance the load flexibility of the LA, making it more effective in wind accommodation.

The agreement price of wind power purchase from the wind farm is also a vital factor that influences the effect of wind accommodation and the revenues of both sides, as respectively shown in Figures 5 and 6 and Table A1. It is indicated that when the agreement price $c_{\text {wind }} \leq 381$, revenues of the wind farm and the LA vary linearly with agreement price changes, while the flexible load dispatch does not reduce the curtailed wind electricity. When $c_{\text {wind }}>1$, on account of high agreement price, the LA first stops dispatching the shiftable loads. While when $c_{\text {wind }}=407$, transferable loads cease transferring, which leads to an increment in curtailed wind electricity and stagnation in the wind farm's revenue growth.

Likewise, the compensation price for flexible loads also has a great influence. Curtailed electricity and revenues of both sides under different compensation prices are given in Figures 7 and 8 , 
respectively. The abscissas of both figures represent the multiple of the initial compensation price in our case. For example, abscissa 2 denotes the costs which the LA needed to compensate for curtailable loads, shiftable loads, and transferable loads, which were $¥ 80 / \mathrm{MW}, ¥ 60 / \mathrm{MW}$, and $¥ 40 / \mathrm{MW}$, respectively. Then, we find that the higher the compensation price, the less wind power the LA accommodates, and a drop of revenues for both the wind farm and the LA is seen. It can also be observed that the impact of compensation price on wind farm revenue was greater than it was on the LA, owing to its steeper downward trend. This is because when the compensation price is rather high, the LA stops dispatching partial flexible loads to ensure its own interest. For instance, when the abscissa was 2, shiftable load 1 ceased shifting. When the abscissa was 4 , the dispatch was cancelled completely.

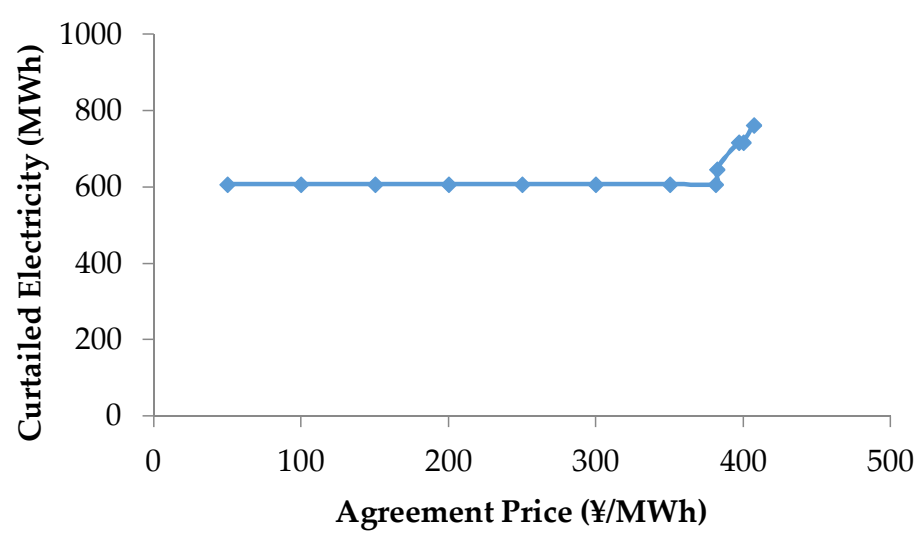

Figure 5. Wind curtailment under different agreement prices.

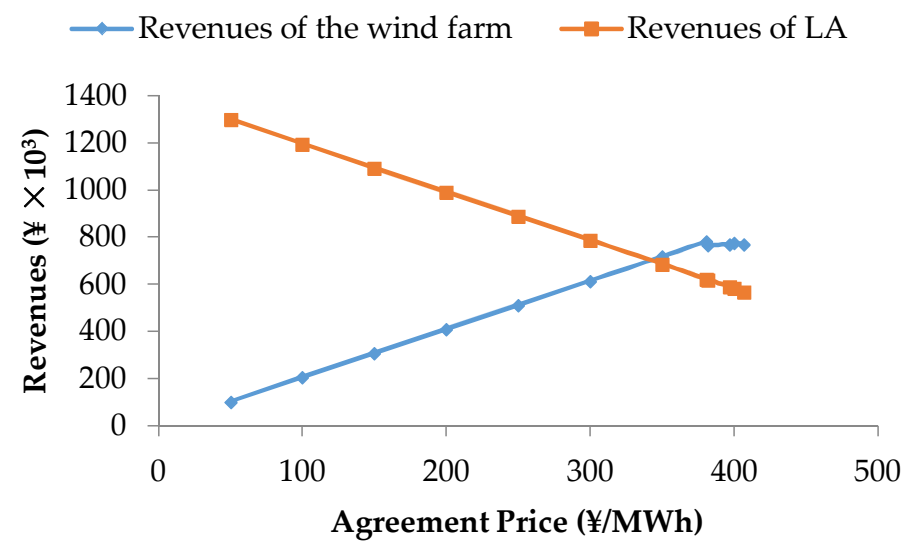

Figure 6. The revenues of both sides under different agreement prices.

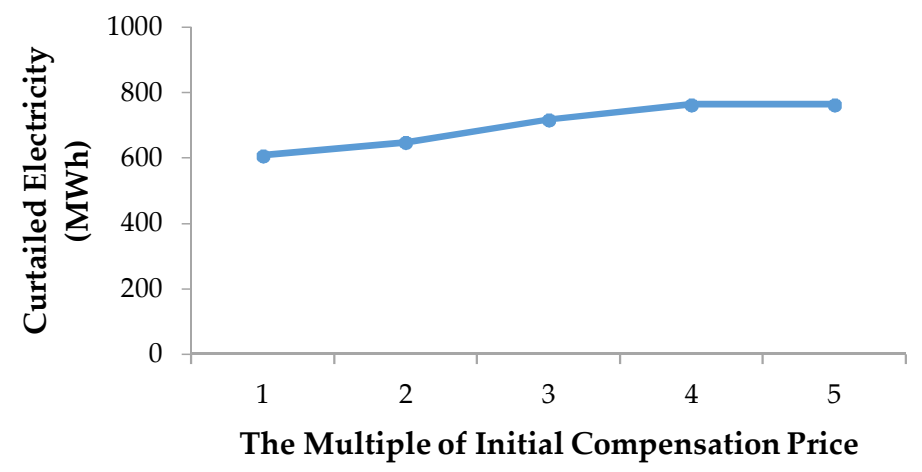

Figure 7. Wind curtailment under different compensation prices. 


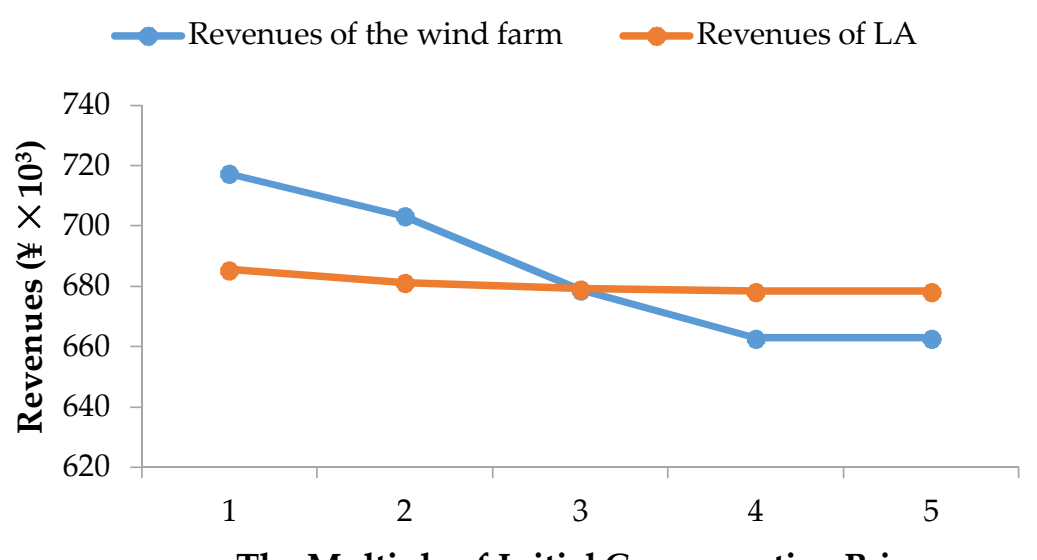

The Multiple of Initial Compensation Price

Figure 8. The revenues of both sides under different compensation prices.

\section{Conclusions}

With full consideration of the electricity consumption characteristics and response capabilities of curtailable loads, shiftable loads, and transferable loads, we put forward a new dispatch mode where the LA buys electricity directly from wind farms and operates in coordination with them to accommodate excess wind power output. Furthermore, aiming to maximize the revenue of the LA, the wind power-load coordinated dispatch model based on agreement price is established. The conclusions are as follows:

- In WLCOM, through the rational dispatching of these three types of flexible loads by the LA, the load curve is effectively ameliorated with wind curtailment drastically reduced and renewable energy accommodation capability enhanced. Additionally, this WLCOM enables fixed loads to effectively accommodate curtailed wind power. Besides, with coordinated operation, both the wind farm and the LA will gain considerable revenues.

- In China, power terminal customers mainly take on extra costs caused by wind accommodation so that accommodation demands are always positive in this paper. Hence, in WLCOM, the LA will not take the initiative to dispatch its curtailable loads; that is, curtailable loads will not respond to the accommodation demands.

- For the given wind farm, the quantity, capacity, and response capability of loads aggregated by the LA all influence the effect of wind power accommodation.

- The agreement price at which the LA buys wind power from the wind farm and the compensation price for flexible loads are key to achieving effective accommodation and considerable revenues for the wind farm and the LA when flexible loads are dispatched reasonably.

With the technical support of a smart grid, using WLCOM to accommodate wind power has large room for growth. Game problems in the process of wind farms and LAs co-accommodating wind power are follow-up topics to this paper.

Author Contributions: L.L. and X.C. conceived and designed the study; X.C. and B.X. performed the experiments and mainly wrote the paper; S.X. contributed to the figures of the case and proofread the paper.

Acknowledgments: This work was supported by the State Grid Corporation of China (No. 5230HQ16000A) and the Beijing Natural Science Foundation of China (No. 3174057).

Conflicts of Interest: The authors declare no conflict of interest. 


\section{Appendix A}

Table A1. Wind curtailment and the revenues of both sides under different agreement prices.

\begin{tabular}{cccc}
\hline $\begin{array}{c}\text { Agreement Price } \\
\text { (¥/MWh) }\end{array}$ & $\begin{array}{c}\text { Curtailed Electricity } \\
\text { (MWh) }\end{array}$ & $\begin{array}{c}\text { Revenue of the Wind Farm } \\
\mathbf{( ¥ )}\end{array}$ & $\begin{array}{c}\text { Revenue of the LA } \\
(¥)\end{array}$ \\
\hline 250 & 607.74 & 512,300 & 890,300 \\
300 & 607.74 & 614,800 & 787,900 \\
350 & 607.74 & 717,300 & 686,600 \\
381 & 607.74 & 780,800 & 621,900 \\
382 & 647.74 & 767,600 & 619,800 \\
397 & 717.74 & 769,900 & 589,700 \\
407 & 763.74 & 770,600 & 570,300 \\
\hline
\end{tabular}

\section{References}

1. Albadi, M.H.; El-Saadany, E.F. Demand Response in Electricity Markets: An Overview. In Proceedings of the Power Engineering Society General Meeting, Tampa, FL, USA, 24-28 June 2007; IEEE: Piscataway, NJ, USA, 2007; pp. 1-5.

2. US Department of Energy. Benefits of Demand Response in Electricity Markets and Recommendations for Achieving Them: Report to the United States Congress. 2006. Available online: http:/ / eetd.lbl.gov (accessed on 23 March 2017).

3. Wang, K.; Yao, J.G.; Yao, Z.L. Survey of research on flexible loads scheduling technologies. Autom. Electr. Power Syst. 2014, 38, 127-135.

4. Sahin, C.; Shahidehpour, M.; Erkmen, I. Allocation of Hourly Reserve versus Demand Response for Security-Constrained Scheduling of Stochastic Wind Energy. IEEE Trans. Sustain. Energy 2013, 4, $219-228$. [CrossRef]

5. Wu, H.; Shahidehpour, M.; Al-Abdulwahab, A. Hourly demand response in day-ahead scheduling for managing the variability of renewable energy. IET Gener. Transm. Distrib. 2013, 7, 226-234. [CrossRef]

6. Khodaei, A.; Shahidehpour, M.; Bahramirad, S. SCUC with Hourly Demand Response Considering Intertemporal Load Characteristics. IEEE Trans. Smart Grid 2011, 2, 564-571. [CrossRef]

7. Zhao, C.; Wang, J.; Watson, J.P.; Guan, Y. Multi-Stage Robust Unit Commitment Considering Wind and Demand Response Uncertainties. IEEE Trans. Power Syst. 2013, 28, 2708-2717. [CrossRef]

8. Ju, L.W.; Qin, C.; Wu, H.L. Wind power accommodation stochastic optimization model with multi-type demand response. Power Syst. Technol. 2015, 39, 1839-1846.

9. Jorge, H.; Antunes, C.H.; Martins, A.G. A multiple objective decision support model for the selection of remote load control strategies. IEEE Trans. Power Syst. 2000, 15, 865-872. [CrossRef]

10. Zeng, J.; Xu, D.D.; Liu, J.F. Multi-objective optimal operation of microgrid considering dynamic loads. Proc. CSEE 2016, 36, 3325-3333.

11. Callaway, D.S. Tapping the energy storage potential in electric loads to deliver load following and regulation with application to wind energy. Energy Convers. Manag. 2009, 50, 1389-1400. [CrossRef]

12. Li, C.Y.; Wang, D.; Zhang, P. Double Layer Real-time Scheduling Model of Independent Microgrid Considering Scheduling Priority of Load Aggregators. Autom. Electr. Power Syst. 2017, 41, 37-43.

13. Rabiee, A.; Sadeghi, M.; Aghaeic, J.; Heidari, A. Optimal operation of microgrids through simultaneous scheduling of electrical vehicles and responsive loads considering wind and PV units uncertainties. Renew. Sustain. Energy Rev. 2016, 57, 721-739. [CrossRef]

14. Drovtar, I.; Uuemaa, P.; Rosin, A.; Kilter, J.; Valtin, J. Using Demand Side Management in Energy-Intensive Industries for Providing Balancing Power-The Estonian Case Study. In Proceedings of the Power and Energy Society General Meeting, Vancouver, BC, Canada, 21-25 July 2013; IEEE: Piscataway, NJ, USA, 2013; pp. 1-5.

15. Hu, Z.; Duan, B.; Xu, Y. Demand Response Optimization of Power Generation and Consumption in Energy Intensive Enterprise. In Proceedings of the IEEE Innovative Smart Grid Technologies-Asia (ISGT ASIA), Bangkok, Thailand, 3-6 November 2015; IEEE: Piscataway, NJ, USA, 2015; pp. 1-6. 
16. Liu, W.Y.; Wen, J.; Xie, C. Multi-objective optimal method considering wind power accommodation based on source-load coordination. Proc. CSEE 2015, 35, 1079-1088.

17. Huang, Q.; Jia, Q.S.; Qiu, Z.; Guan, X.; Deconinck, G. Matching EV Charging Load with Uncertain Wind: A Simulation-Based Policy Improvement Approach. IEEE Trans. Smart Grid 2015, 6, 1425-1433. [CrossRef]

18. Sun, C.; Wang, L.J.; Xu, H.L. An interaction load model and its application in microgrid day-ahead economic scheduling. Power Syst. Technol. 2016, 40, 2009-2015.

19. Jing, Z.X.; Hu, R.X.; Yuan, Z.X. Capacity configuration for island microgrid with wind/solar/pumped storage considering demand response. Autom. Electr. Power Syst. 2017, 41, 65-72.

20. California Independent System Operator. Process for Participating Load Program (Ancillary Services/Supplemental Energy); California Independent System Operator: Folsom, CA, USA, 2008.

21. Dominguez-Garcia, A.D.; Hadjicostis, C.N. Distributed Algorithms for Control of Demand Response and Distributed Energy Resources. In Proceedings of the Decision and Control and European Control Conference, Orlando, FL, USA, 12-15 December 2011; IEEE: Piscataway, NJ, USA, 2011; pp. 27-32.

22. Zhang, J.Y.; Wang, L.; Liu, S.G. Cost-Benefit Analysis of load aggregator participating in interruptible load program. South. Power Syst. Technol. 2016, 10, 74-81.

23. Sun, Y.; Xu, P.; Shan, B.G. Road map for "internet plus" energy substitution in electricity retail market reform in China. Power Syst. Technol. 2016, 40, 3648-3654.

24. Farhangi, H. The path of the smart grid. IEEE Power Energy Mag. 2010, 8, 18-28. [CrossRef]

25. Siano, P. Demand response and smart grids-A survey. Renew. Sustain. Energy Rev. 2014, 30, 461-478. [CrossRef]

26. Rahimi, F.; Ipakchi, A. Demand response as a market resource under the smart grid paradigm. IEEE Trans. Smart Grid 2010, 1, 82-88. [CrossRef]

27. National Energy Administration. China's Operation of Wind Power Integration in 2016. Available online: http:/ / www.nea.gov.cn/2017-01/26/c_136014615.htm (accessed on 23 March 2017).

28. Aalami, H.A.; Moghaddam, M.P.; Yousefi, G.R. Demand response modeling considering Interruptible/Curtailable loads and capacity market program. Appl. Energy 2010, 87, 243-250. [CrossRef]

29. Graditi, G.; Silvestre, M.L.D.; Gallea, R. Heuristic-Based Shiftable Loads Optimal Management in Smart Micro-Grids. IEEE Trans. Ind. Inf. 2015, 11, 271-280. [CrossRef]

30. Mohsenian-Rad, H. Optimal Demand Bidding for Time-Shiftable Loads. IEEE Trans. Power Syst. 2015, 30, 939-951. [CrossRef]

31. Brook, A.; Kendrick, D.; Meeraus, A. GAMS, a user's guide. ACM Signum Newsl. 1988, 23, 10-11. [CrossRef]

32. The GAMS Software Website. Available online: https://www.gams.com/latest/docs/ (accessed on 23 March 2017).

33. Zhong, H.W.; Xia, Q.; Zhang, J. Mechanism design for incentivizing wing farms to improve power forecast accuracy. Autom. Electr. Power Syst. 2015, 39, 47-53.

34. Brunetto, C.; Tina, G. Wind generation imbalances penalties in day-ahead energy markets: The Italian case. Electr. Power Syst. Res. 2011, 81, 1446-1455. [CrossRef]

(C) 2018 by the authors. Licensee MDPI, Basel, Switzerland. This article is an open access article distributed under the terms and conditions of the Creative Commons Attribution (CC BY) license (http://creativecommons.org/licenses/by/4.0/). 